\title{
Pengenalan Teks pada Objek-Objek Wisata di Sulawesi Utara dengan Teknologi Augmented Reality
}

\author{
Rendy F. Raranta ${ }^{1)}$, Alicia A. E. Sinsuw ${ }^{2)}$, Brave A. Sugiarso ${ }^{3)}$ \\ Teknik Informatika Universitas Sam Ratulangi \\ 120216135@student.unsrat.ac.id ${ }^{1)}$,xnajoan@unsrat.ac.id ${ }^{2)}$, brave@ unsrat.ac.id ${ }^{3)}$
}

\begin{abstract}
Abstrak - Sulawesi Utara merupakan daerah yang memiliki keindahan pariwisata dimana Sulawesi Utara dikelilingi berbagai macam wisata alam, wisata buatan dan wisata budaya sehingga banyak turis local dan turis asing yang berkunjung untuk menikmati keindahan pariwisata di Sulawesi Utara. Terlebih lagi, Masyarakat Ekonomi ASEAN (MEA), mengakibatkan semakin besarnya jumlah kedatangan turis asing baik turis maupun pebisnis asing, dengan demikian terbuka kesempatan untuk mengeksplorasi berbagai tempat wisata di Indonesia lebih khusus Sulawesi Utara. Namun MEA memiliki suatu masalah dalam hal interaksi antara Bahasa dari turis/pebisnis asing dan Bahasa Indonesia, yang memungkinkan terjadinya diskomunikasi antara masyarakat lokal dan turis asing karena berbedanya Bahasa di tiap Negara.

Augmented Reality adalah teknologi dengan konsep menggabungkan secara realtime terhadap digital content yang dibuat oleh komputer dengan dunia nyata. Penelitian ini bertujuan untuk membangun aplikasi berbasis teknologi augmented reality (AR) dengan menampilkan terjemahan Bahasa daerah di tempat wisata menjadi Bahasa Inggris dan Mandarin. Teknologi augmented reality dapat membantu visualisasi lebih detail dan lebih interaktif dengan menerapkan cara scan marker tulisan dimana keluarannya adalah Bahasa Inggris dan Mandarin. Penelitian ini menggunakan metode pengembangan perangkat lunak Multimedia Development Life Cycle (MDLC). Hasil dari penelitian ini adalah sebuah aplikasi berbasis teknologi Augmented reality yang bisa menampilkan terjemahan Bahasa daerah di tempat wisata menjadi Bahasa Inggris dan Mandarin.
\end{abstract}

Kata Kunci : Augmented Reality, Pariwisata, Sulawesi Utara, Turis.

\section{PENDAHULUAN}

Indonesia merupakan Negara kepulauan yang memiliki berbagai macam suku dan bahasa, selain itu juga Indonesia merupakan Negara yang memiliki keindahan laut, pantai, pegunungan, dan berbagai keunikan budaya yang terdapat di tiap-tiap daerah. Sulawesi Utara merupakan salah satu daerah yang memiliki semua aspekaspek keindahan tersebut, dimana Sulawesi utara dikelilingi berbagai macam wisata alam, wisata buatan dan wisata budaya. Terlebih lagi, Masyarakat Ekonomi ASEAN (MEA), yang telah dimulai pada akhir tahun 2015, mengimplikasikan hubungan dagang yang lebih intensif di wilayah ASEAN sehingga mengakibatkan semakin besarnya jumlah kedatangan turis asing baik turis maupun pebisnis asing, dengan demikian terbuka kesempatan untuk mengeksplorasi berbagai tempat wisata di Indonesia lebih khusus Sulawesi Utara.

Namun MEA memiliki suatu masalah dalam hal interaksi antara Bahasa dari turis/pebisnis asing dan Bahasa Indonesia, yang memungkinkan terjadinya diskomunikasi antara masyarakat lokal dan turis asing karena berbedanya Bahasa di tiap Negara. Dari permasalahan tersebut dibutuhkan suatu teknologi dalam membantu turis asing untuk berkunjung di tempat-tempat wisata di Sulawesi Utara. Teknologi Augmented Reality dapat membantu dengan menampilkan visualisasi lebih detail dan lebih interaktif dengan menerapkan cara scan marker tulisan dengan keluaran adalah Bahasa Inggris dan Mandarin. sehingga akan mempermudah memahami dan membantu penyampaian informasi di tempat wisata.

\section{LANDASAN TEORI}

\section{A. Augmented Reality}

Augmented Reality adalah teknologi yang menggabungkan benda virtual 2D atau 3D ke dalam lingkungan nyata bersifat interaktif dan real time (Azuma, 1997).

Menurut penjelasan Haller, Billinghurst, dan Thomas (2007), riset Augmented Reality bertujuan untuk mengembangkan teknologi yang memperbolehkan penggabungan secara real-time terhadap digital content yang dibuat oleh komputer dengan dunia nyata. Augmented Reality memperbolehkan pengguna melihat objek maya dua dimensi atau tiga dimensi yang diproyeksikan terhadap dunia nyata. (Emerging Technologies of Augmented Reality: Interfaces and Design). Teknologi AR ini dapat menyisipkan suatu informasi tertentu ke dalam dunia maya dan menampilkannya di dunia nyata dengan bantuan perlengkapan seperti webcam, komputer, HP Android, maupun kacamata khusus. User ataupun pengguna didalam dunia nyata tidak dapat melihat objek maya dengan mata telanjang, untuk mengidentifikasi objek dibutuhkan perantara berupa komputer dan kamera yang nantinya akan menyisipkan objek maya ke dalam dunia nyata.

Metode yang dikembangkan pada Augmented Reality saat ini terbagi menjadi dua metode, yaitu Marker Based Tracking dan Markless Augmented Reality.

1. Marker Augmented Reality (Marker Based Tracking)

Marker biasanya merupakan ilustrasi hitam dan putih persegi dengan batas hitam tebal dan latar belakang putih. Komputer akan mengenali posisi dan orientasi marker dan menciptakan dunia virtual 3D yaitu titik $(0,0,0)$ dan tiga sumbu yaitu X, Y, dan Z. Marker Based Tracking ini sudah lama dikembangkan sejak 1980-an dan 
pada awal 1990-an mulai dikembangkan untuk penggunaan Augmented Reality.

2. Markerless Augmented Reality

Salah satu metode Augmented Reality yang saat ini sedang berkembang adalah metode "Markerless Augmented Reality", dengan metode ini pengguna tidak perlu lagi menggunakan sebuah marker untuk menampilkan elemenelemen digital, dengan tool yang disediakan Qualcomm untuk pengembangan Augmented Reality berbasis mobile device, mempermudah pengembang untuk membuat aplikasi yang markerless.

\section{B. Vuforia}

Vuforia adalah Software Development Kit (SDK) yang di gunakan pada perangkat mobile untuk pembuatan aplikasi Augmented Reality. SDK ini menggunakan teknologi computer vision untuk mengenali dan melacak gambar target dan objek 3D yang sederhana secara real time. Dengan kemampuan ini, memungkinkan para developer untuk membuat posisi dan orientasi objek virtual seperti model 3D dan media-media lainnya yang berkaitan dengan dunia nyata dapat dilihat melalui kamera dari perangkat mobile. Objek virtual tersebut selanjutnya melacak posisi orientasi dari gambar secara real-time sehingga perspektif dari pengguna pada objek tersebut sesuai dengan perspektif mereka pada target gambar.sehingga terlihat bahwa objek virtual tersebut adalah bagian dari dunia nyata (Azhar dkk, 2014).

Proses pengembangan Vuforia memiliki dua area cakupan yaitu dari segi developer dan dari segi Vuforia. Untuk membuat image target, developer harus mengunggah file gambar misalnya *.jpg ke target management system yang ada di website developer Vuforia, kemudian mengunduh lagi dalam bentuk dataset yang akan disimpan dalam device target database agar bisa dibaca dan dimanipulasi oleh Vuforia engine (Kereh dkk, 2015)

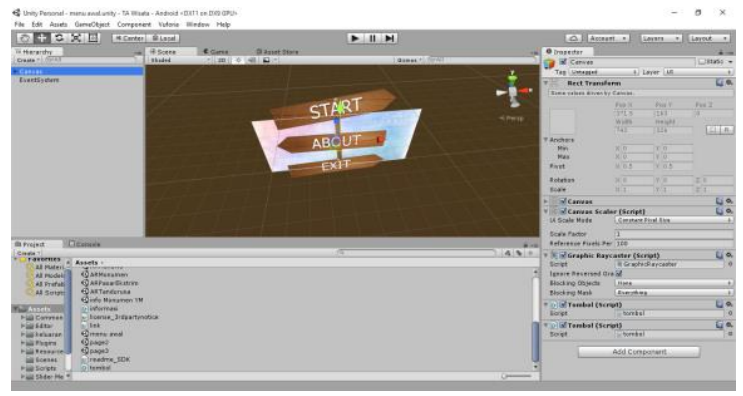

Gambar 1 Tampilan awal softwere Unity 3D

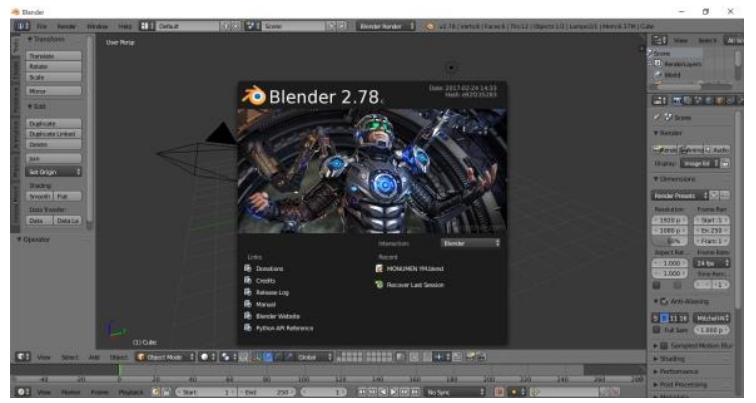

Gambar 2 Tampilan Blender 3D
Wisata di Sulawesi Utara dengan Teknologi Augmented Reality

C. Unity $3 D$

Unity Game Engine adalah salah satu tools crossplatform yang dikembangkan oleh Unity Technologies untuk menciptakan game. Termasuk dalam mengembangkan game untuk situs web, platform desktop, dan smartphone. Unity Engine dapat mengolah beberapa data seperti 3D, suara, teksture, dan lain sebagainya. Bahasa pemrograman yang digunakan seperti Javascript, C\# dan Boo. Vuforia sendiri menyediakan SDK khusus untuk Unity dengan nama Vuforia AR Extension for Unity (Kereh dkk, 2015).

Unity (lihat pada gambar 1) secara rinci dapat digunakan untuk membuat video game $3 \mathrm{D}$, real time animasi 3D dan visualisasi arsitektur dan isi serupa yang interaktif lainnya. Editor Unity dapat menggunakan plugin untuk web player dan menghasilkan game browser yang didukung oleh Windows dan Mac. Plugin web player dapat juga dipakai untuk widgets Mac. (Yusuf dkk, 2015).

\section{Blender $3 D$}

Menuru penjelasan Nugroho (2016), Blender (lihat pada gambar 2) adalah aplikasi grafis 3D Open Source di bawah naungan GNU (General Public License). Blender bisa digunakan untuk modeling, texturing, $U V$ unwrapping, rigging, water simulation, animating, skinning, rendering, particle, simulations, non-linear editing, compositing, dan membuat interactive $3 D$ application, termasuk games.

\section{METODOLOGI PENELITIAN}

\section{A. Kerangka Berpikir}

Kerangka berpikir (Gambar 3 Kerangka Pikir) merupakan alur berpikir yang disusun untuk menjelaskan bagaimana sebuah penelitian dilakukan dari awal, proses pelaksanaan, hingga akhir.

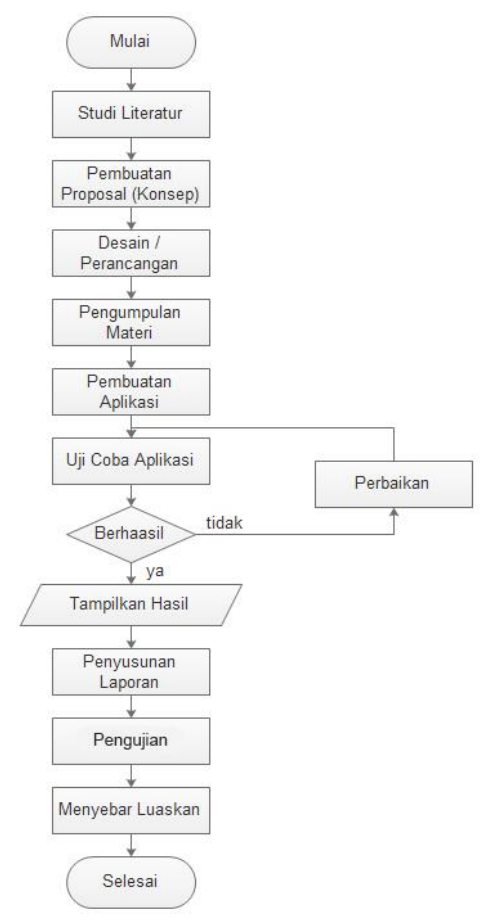

Gambar 3 Kerangka Pikir 


\section{B. Metodologi Penelitian}

Metodologi yang digunakan dalam penelitian tugas akhir ini adalah sebagai berikut:

1) Metode Pengembangan

Metode pengembangan aplikasi (MDLC) Multimedia Development Life Cycle (lihat gambar 4) dimana metode ini memiliki 6 tahapan, yaitu concept, design, material collecting, assembly, testing dan distribution.

a) Concept

Dalam tahapan ini ada beberapa tahap yang perlu diperhatikan, antara lain:

1. Menentukan tujuan aplikasi yaitu untuk mempermudah pengenalan tempat wisata di Sulawesi Utara menggunakan bahasa Inggris dan Mandarin dengan teknologi Augmented Reality.

2. Deskripsi Aplikasi Pengenalan Teks berbasis teknologi Augmented Reality ini berjalan dan dioperasikan pada perangkat bersistem operasi android.

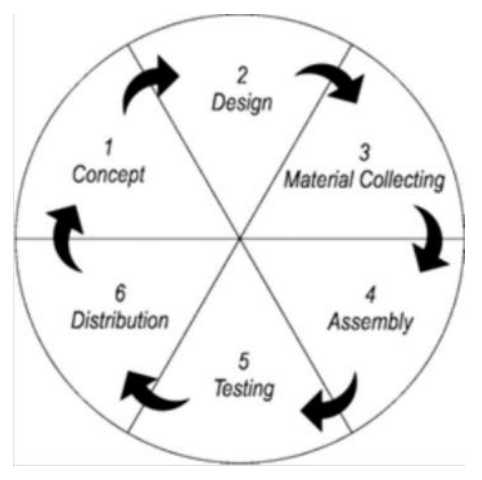

Gambar 4 Multimedia Development Life Cycle (MDLC) (Sutopo dkk, 2012).

Tabel 1 Storyboard menu utama

\begin{tabular}{|c|c|c|}
\hline \multicolumn{3}{|l|}{ Multimedia Storyboard } \\
\hline \multicolumn{3}{|c|}{ Project: Text Recognition Augmented Rality } \\
\hline \multicolumn{2}{|l|}{ Screen: 1} & ScreenID:Main Menu \\
\hline & Mulai & JUDUL \\
\hline & Tentang & \\
\hline & Keluar & \\
\hline \multirow{2}{*}{\multicolumn{3}{|c|}{$\begin{array}{l}\text { Screen Description: } \\
\text { Pada rancangan tampilan ini, pengguna akan melakukan pemilihan } \\
\text { untuk pilihan yang sudah disediakan. Terdapat tiga pilihan yaitu } \\
\text { "Memulai" untuk masuk pada tampilan menu selanjutnya, "Exit" } \\
\text { untuk keluar dari aplikasi. }\end{array}$}} \\
\hline & & \\
\hline \multicolumn{2}{|l|}{ Link From Screen ID: - } & $\begin{array}{l}\text { Link to Screen ID: } \\
\text { Menu Slider }\end{array}$ \\
\hline \multicolumn{3}{|l|}{ Text Attribut: } \\
\hline \multicolumn{3}{|c|}{ Still Image: Destinasi/tujuan } \\
\hline Audio: - & & \\
\hline
\end{tabular}

b) Design

Tahapan ini meliputi tahap pembuatan tampilan dan kebutuhan material untuk pengembangan aplikasi menggunakan storyboard (bisa dilihat pada table 2).

c) Material Collecting

\section{Data Primer}

Data-data tersebut diperoleh dari hasil wawancara serta observasi di lapangan. Peneliti mengumpulkan data yang di peroleh secara langsung dari Dinas Pariwisata Provinsi Sulawesi Utara. Data yang diperoleh dari dinas pariwisata provinsi sulawesi utara berupa daftar wisata-wisata di sulawesi utara yang sudah terdaftar di dinas pariwisata. Data Pariwisata yang terdaftar pada tahun 2015 dari Dinas Pariwisata Provinsi Sulawesi Utara yang mempunyai 15 Kabupaten Kota (bisa dilihat pada table 2).

\section{Kuisioner}

Kuisioner yang mengumpulkan data dengan cara memberikan beberapa pertanyaan atau pernyataan tertulis yang berhubungan dengan penelitaan yang sedang dilakukan kepada responden (bisa dilihat pada table 3).

Tabel 2. Data Pariwisata Pemprov Sulut 2015

\begin{tabular}{|l|l|}
\hline Total Pariwisata & $\mathbf{7 0 8}$ \\
\hline Wisata Alam & 501 \\
\hline Wisata Budaya & 155 \\
\hline Wisata Buatan & 52 \\
\hline
\end{tabular}

Table 3 Kuisioner penelitian

\begin{tabular}{|c|c|c|c|c|c|}
\hline \multirow{2}{*}{ No } & \multirow{2}{*}{ Pernyataan } & \multicolumn{4}{|c|}{ SKALA } \\
\hline & & SS & 5 & TS & STS \\
\hline 1 & $\begin{array}{l}\text { Sulawesi Utara adalah daerab } \\
\text { potensi wisata yang baik di } \\
\text { Indonesia }\end{array}$ & & & & \\
\hline 2 & $\begin{array}{l}\text { Banaka turis asing yang datang } \\
\text { di Sulawesi Utara. }\end{array}$ & & & & \\
\hline 3 & $\begin{array}{l}\text { Rata-rata turis asing berasal } \\
\text { dari Negara China }\end{array}$ & & & & \\
\hline 4 & $\begin{array}{l}\text { Babasa loggris adalah bahasa } \\
\text { yang seriog digunakan oleb } \\
\text { turis asing }\end{array}$ & & & & \\
\hline 5 & $\begin{array}{l}\text { Maveritas orang menggunakan } \\
\text { smartphone }\end{array}$ & & & & \\
\hline 6 & $\begin{array}{l}\text { Untuk memperkenalkan } \\
\text { potensi wisata di Sulawesi } \\
\text { Utara dapat. } \\
\text { dijoplementasikan dalam } \\
\text { bentuk aplikasj. }\end{array}$ & & & & \\
\hline 7 & $\begin{array}{l}\text { Media interaktif seperti } \\
\text { Augmented Reality dapat. } \\
\text { mecobantu dalare } \\
\text { mecopromosikan pariwisata di } \\
\text { Sulawesi Utara }\end{array}$ & & & & \\
\hline 8 & $\begin{array}{l}\text { Dalam memperkenalkan } \\
\text { potensi wisata membutubkan } \\
\text { media pengenalan yang } \\
\text { interaktif sepecti teknolggi } \\
\text { Augmented Reality. }\end{array}$ & & & & \\
\hline
\end{tabular}


Rendy Frits Raranta - Pengenalan Teks pada Objek-Objek Wisata di Sulawesi Utara dengan Teknologi Augmented Reality

d) Assembly

Tahap pembuatan aplikasi, materi-materi serta file-file yang sudah didapat kemudian dirangkai dan disusun sesuai desain.

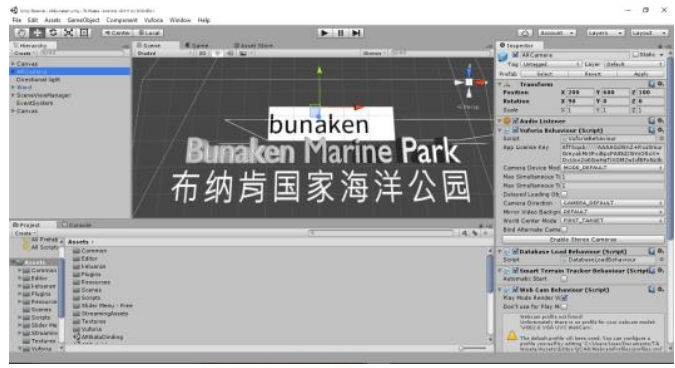

Gambar 5 Pembuatan aplikasi

Gambar 5 merupakan tampilan pada saat pembuatan augmented reality pengenalan teks, tulisan bunaken merupakan marker untuk di scan lalu akan menampilkan terjemahan Taman Laut Bunaken dalam bahasa Inggris dan Mandarin. Pengukuran posisi dan rotasi kamera dan objek sangat berpengaru untuk menampilkan output dan mendeteksi marker tulisan sebagai target.

\section{HASIL DAN PEMBAHASAN}

A. Aplikasi Pengenalan Teks pada Objek Wisata

1) Tampilan Menu Utama

Gambar 6 merupakan Menu utama aplikasi pengenalan teks objek wisata. Scene menu utama terdiri dari Tombol start, about, dan exit.

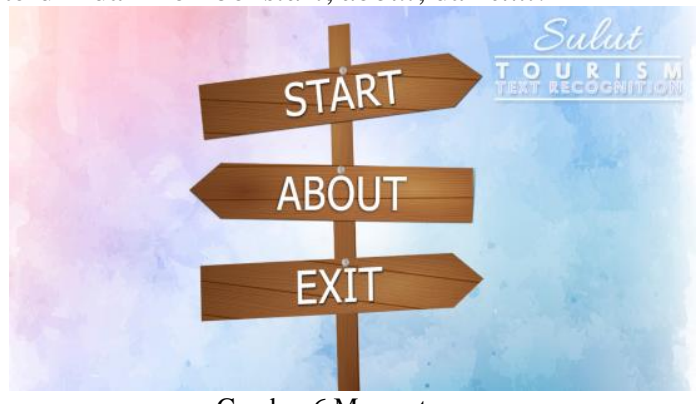

Gambar 6 Menu utama

2) Tampilan menu tempat wisata

Gambar 7 merupakan tampilan menu tempat wisata yang ditampilkan dengan menu slider, scroll ke kiri atau scroll ke kanan untuk memilih tempat wisata.

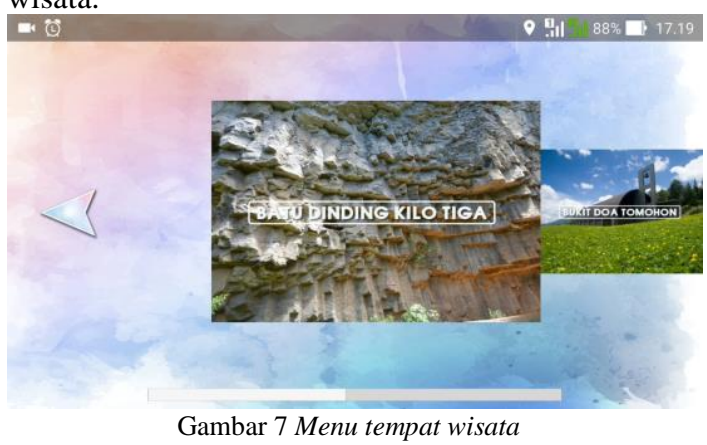

3) Tampilan scan marker tulisan

Gambar 8 merupakan tampilan scan marker tulisan pada media cetak Koran, dimana ketika objek tulisan dapat dikenal, maka aplikasi akan menampilkan objek 3D dalam bahasa Inggris dan Mandarin.

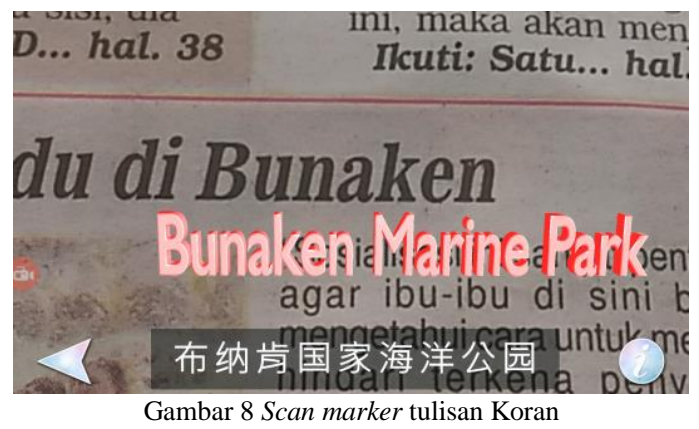

Gambar 9 merupakan tampilan scan marker tulisan di tempat wisata, dimana ketika aplikasi mengenali pola marker, maka akan ditampilkan Objek 3D dalam bahasa Inggris dan Mandarin.

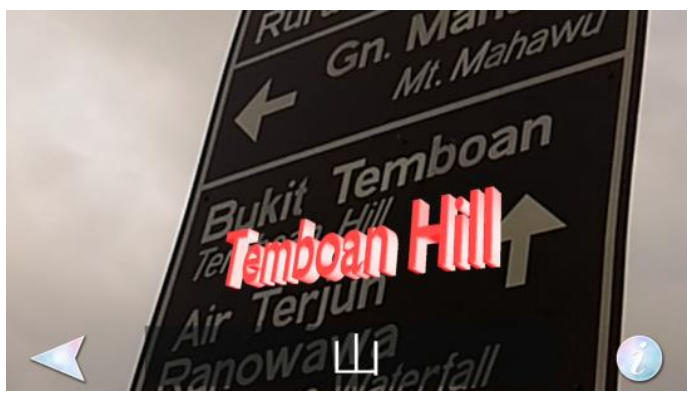

Gambar 9 Scan marker tulisan di tempat wisata

4) Tampilan informasi tempat wisata

Gambar 10 merupakan tampilan informasi tempat wisata ketika memilih tombol (i) pada gambar 9, informasi yang dikeluarkan dalam bahasa Inggris dan Mandarin.

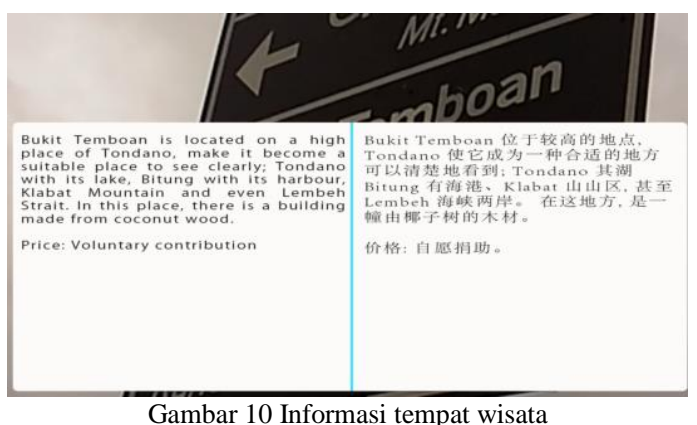

\section{B. Alpha Testing}

Pengujian yang digunakan adalah pengujian Alpha. Pada proses pengujian alpha ini dilakukan pada priview aplikasi sebelum di Publish menjadi file .apk, dilakukan pengujian untuk memastikan semua fitur dan tombol yang ada didalam aplikasi berjalan dengan baik sebelum di publikasikan (bisa dilihat pada table 4). 
Tabel 4 Alpha Testing

\begin{tabular}{|c|c|c|c|c|c|}
\hline \multirow{2}{*}{ No } & \multirow{2}{*}{ Item Pengujian } & \multicolumn{3}{|c|}{ Hasil } & \multirow{2}{*}{$\begin{array}{c}\text { Keteran } \\
\text { gan }\end{array}$} \\
\hline & & Baik & Kurang & Tidak & \\
\hline 1 & Halaman Awal & $\underline{\checkmark}$ & & & Berhasil \\
\hline 2 & $\begin{array}{c}\text { Halaman pilih tempat } \\
\text { wisata }\end{array}$ & $\checkmark$ & & & Berhasil \\
\hline 3 & $\begin{array}{l}\text { Halaman pilih tempat } \\
\text { wisata halaman ke-2 }\end{array}$ & $\underline{\checkmark}$ & & & Berhasil \\
\hline 4 & $\begin{array}{c}\text { Halaman informasi tempat } \\
\text { wisata }\end{array}$ & $\checkmark$ & & & Berhasil \\
\hline 5 & Halaman informasi aplikasi & $\checkmark$ & & & Berhasil \\
\hline 6 & Scene Bunaken & $\checkmark$ & & & $\underline{B e r h a s i l}$ \\
\hline 7 & $\begin{array}{c}\text { Scene Monumen Yesus } \\
\text { Memberkati }\end{array}$ & & $\checkmark$ & & $\begin{array}{c}\text { Objek } \\
\text { terlalu } \\
\text { kecil } \\
\text { pada } \\
\text { kamera }\end{array}$ \\
\hline 8 & Scene Gunung Mahawu & $\underline{\checkmark}$ & & & Berhasil \\
\hline$\underline{9}$ & Scene Taman Tandurusa & $\underline{v}$ & & & Berhasil \\
\hline$\underline{10}$ & $\underline{\text { Scene Pasar Ekstrim }}$ & $\sqrt{ }$ & & & Berhasil \\
\hline$\underline{11}$ & $\begin{array}{c}\text { Scene Batu Dinding Kilo } \\
\text { Tiga }\end{array}$ & $\checkmark$ & & & Berhasil \\
\hline$\underline{12}$ & Scene Bukit Doa Tomohon & $\sqrt{ }$ & & & Berhasil \\
\hline$\underline{13}$ & Scene Bukit Kasih & $\underline{\checkmark}$ & & & Berhasil \\
\hline$\underline{14}$ & Scene Bukit Temboan & $\underline{v}$ & & & $\underline{\text { Berhasil }}$ \\
\hline$\underline{15}$ & Scene Danau Linow & $\underline{\checkmark}$ & & & Berhasil \\
\hline 16 & Tombol Start & $\underline{\checkmark}$ & & & $\underline{B e r h a s i l}$ \\
\hline 17 & Tombol About & $\underline{\checkmark}$ & & & Berhasil \\
\hline 18 & Tombol Exit & $\underline{\checkmark}$ & & & Berhasil \\
\hline 19 & Tombol next & $\underline{\checkmark}$ & & & $\underline{B e r h a s i l}$ \\
\hline 20 & Tombol back & & & & Berhasil \\
\hline 21 & Tombol information & $\checkmark$ & & & $\underline{B e r h a s i l}$ \\
\hline
\end{tabular}

\section{PENUTUP}

A. Kesimpulan

Aplikasi Pengenalan Teks pada Objek-Objek Wisata di Sulawesi Utara dengan Teknologi Augmented Reality telah berhasil di bangun dengan teknologi markerless Augmented Reality berbasis Android menggunakan metode pengembangan aplikasi Multimedia Development Life Cycle (MDLC).

B. Saran

Setelah melakukan penelitian maka disarankan:

1) Menambah objek wisata dan fitur-fitur tambahan lainnya.

2) Aplikasi dapat dikembangkan dalam sistem operasi lain, seperti iOS, windows phone atau lainnya.

\section{DAFTAR REFERENSI}

[1] Azhar, N. F., Cahyono, E. B., \& Wicaksono, G. W. (2014). PEMANFAATAN AUGMENTED REALITY UNTUK GAME "RANGER TARGET" FPS BERBASIS ANDROID MENGGUNAKAN UNITY 3D DAN VUFORIA SDK. 2-3.

[2] Azuma, R.T. 1997. A Survey of Augmented Reality. Teleoperators and Virtual Environments, Vol. 6, No. 4, pp. 355-385
[3] Kereh, K. L., Sondakh, R., \& Wahyudi, A. (2015). PENGENALAN TOKOH-TOKOH PAHLAWAN NASIONAL INDONESIA MENGGUNAKAN AUGMENTED REALITY BERBASIS ANDROID. KNSI 2015, 309-310.

[4] Nugroho, C. A. (2017, April 19). Mengenal Blender, Aplikasi Pembuat Animasi 3D. Retrieved from AgungPedia.com: http://www.agungpedia.com/2016/10/mengenal-blenderaplikasi-pembuat.html

[5] Sutrisno, A., Lumenta, A., \& Robot, J. (2014). Implementasi Teknologi Augmented Reality pada Agen Penjualan Rumah. Ejournal Teknik Elektro dan Komputer, 19-21.

[6] Sutopo, Ariesto Hadi. 2012. Teknologi Informasi dan Komunikasi dalam Pendidikan. Yogyakarta: Graha Ilmu

[7] Yusuf, R. M., \& Aristiawan. (2016, July 3). Unity 3D - Game Engine. Retrieved from HermanClass: http://www.hermantolle.com/class/docs/unity-3d-game-en

\section{SEKILAS TENTANG PENULIS}

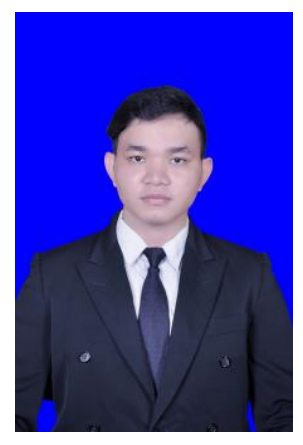

Saya bernama Rendy Frits Raranta dan merupakan anak kedua dari dua bersaudara dalam keluarga, lahir di Manado pada tanggal 15 Juli 1994.

Saya mulai menempuh pendidikan di sekolah dasar SDN Kalasey (2000 - 2006), Kemudian melanjutkan studi tingkat pertama di SMP N 8 Manado (2006 - 2009), dan selanjutnya saya menempuh pendidikan tingkat atas di SMK Negeri 6 Manado (2009 - 2012). Setelah itu, di tahun 2012 saya melanjutkan pendidikan ke salah satu perguruan tinggi yang berada di Manado yaitu Universitas Sam Ratulangi Manado, dengan mengambil Program Studi S-1 Teknik Informatika di Jurusan Elektro Fakultas Teknik. 